Sprache und Metrum

Christoph Küper 

Christoph Küper

\section{Sprache und Metrum}

Semiotik und Linguistik des Verses

Max Niemeyer Verlag Tübingen 1988 


\section{Meinen Eltern, meiner Frau, meinen Kindern}

Gedruckt mit Unterstützung der Deutschen Forschungsgemeinschaft

CIP-Titelaufnahme der Deutschen Bibliothek

Küper, Christoph:

Sprache und Metrum : Semiotik u. Linguistik d. Verses / Christoph Küper. - Tübingen : Niemeyer, 1988

ISBN 3-484-10574-7

Max Niemeyer Verlag Tübingen 1988

Alle Rechte vorbehalten. Ohne Genehmigung des Verlages ist es nicht gestattet, dieses Buch oder Teile daraus photomechanisch zur vervielfältigen.

Printed in Germany. Satz: Bernhard Walter, Tübingen.

Druck: Allgäuer Zeitungsverlag GmbH, Kempten.

Einband: Heinr. Koch, Tübingen 